\title{
Teocomunicação
}

Revista de Teologia da PUCRS

Programa de Pós-Graduação em Teologia

Escola de Humanidades

Porto Alegre, v. 48, n. 1, p. 122-132, janeiro-junho 2018

http://dx.doi.org/10.15448/0103-314X.2018.1.30576

TEOLOGIA E QUESTÕES CONTEMPORÂNEAS

\section{Um canto simples, de amor e verdade: aspectos teológicos da música nativista gaúcha}

\section{A simple song about love and truth: theological aspects of southern Brazilian folk music \\ Renato Ferreira Machado*}

\section{RESUMO}

Em nosso artigo analisamos algumas aproximações entre teologia e música nativista gaúcha, tendo como enfoque a produção teológica na América Latina à época do florescimento do Movimento Nativista. Inicialmente, contextualizamos essa cena musical no ciclo das canções de protesto latino-americanas, ocorrido entre a década de 60 e a década de 80 do Século XX, buscando, ao mesmo tempo, caracterizar o específico do cancioneiro nativista do Rio Grande do Sul. Prosseguimos com os aportes teológicos predominantes na América Latina no contexto estudado e concluímos com a análise de uma canção produzida neste cenário musical.

Palavras-chave: Música Nativista. Teologia da Libertação. América Latina.

\section{ABSTRACT}

In this article we analyze some approaches between theology and Gaucho nativist music, focusing on the theological production in Latin America at the time of the flowering of the Nativist Movement. Initially, we contextualized this musical scene in the cycle of Latin American protest songs, which occurred between the 60s and 80 s of the 20th Century, while at the same time seeking to characterize the specific of the nativist songbook in Rio Grande do Sul. With the predominant theological contributions in Latin America in the studied context, we conclude with the analysis of a song produced in this musical scene.

Keywords: Nativist Music. Liberation Theology. Latin America.

\footnotetext{
* Professor do corpo docente permanente do Programa de Pós-graduação em Memória Social e Bens Culturais. Doutor em Teologia pelas Faculdades EST. Mestre em Teologia e Especialista em Ensino Religioso pela PUCRS. Pedagogo com ênfase em Orientação Educacional pela FAFIMC. <renatoferreiramachado@gmail.com>.
} 


\section{INTRODUÇÃO}

A Música Nativista Gaúcha foi um fenômeno cultural ocorrido no Estado do Rio Grande do Sul ao longo das décadas de 70, 80 e parte da década de 90, através de um movimento de renovação das regionalidades do estado. Seu florescimento se deu nos festivais nativistas que, a começar pela Califórnia da Canção Nativa de Uruguaiana, se espalharam pelo estado e se mantiveram por cerca de trinta anos ${ }^{1}$. Nestes festivais o cancioneiro regional do estado ganhou uma verdadeira renovação através de novos músicos, compositores e cantores que apresentavam um verdadeiro hibridismo lírico, no qual os ritmos folclóricos gaúchos dialogavam com experimentações instrumentais, vocais e, sobretudo, temáticas. É nesse sentido que propomos o presente artigo: o repertório nativista, constantemente, apresenta letras com fortes críticas sociais sintonizadas com sua época e discutidas através do universo simbólico e cultural característico da região pampeana e fronteiriça do Rio Grande do Sul. Nestas elaborações culturais temos identificado fortes traços religiosos que se integram às crônicas sociais da música nativista e, via de regra, enriquecem e fortalecem esse mesmo discurso musical. Esses traços ou forças religiosas apresentam, em sua forma, uma semântica muito próxima à Teologia da Libertação - conforme se elaborava na época - integrada ao folclore $\mathrm{e}$ às místicas originárias latino-americanas. Esse ideário religioso, na grande maioria dos casos apresentado em letras que integram a fé à vida cotidiana campesina do Rio Grande do Sul, parece aproximar este estilo musical das características dos discursos proféticos bastante característicos na teologia oriunda da América Latina daquela época.

Em nosso artigo, assim, trabalharemos com a caracterização de uma semântica profética no cancioneiro nativista. Para tanto, contextualizaremos o nascimento do Movimento Nativista, identificando suas produções musicais e caracterizando suas narrativas e discursos. Junto a isso, abordaremos as principais características do discurso profético original e a mediação deste na América Latina através da teologia elaborada na época mais forte do movimento nativista. Por último, cruzaremos essas informações em algumas músicas produzidas no mesmo contexto, demonstrando as forças religiosas de teor profético nelas presente. Pretendemos, com esse exercício de mediação teológicocultural, contribuir para uma compreensão mais aprofundada de nossas expressões artístico-culturais e para uma leitura de realidade mais embasada e comprometida. Todas essas questões vêm sendo pesquisadas em nosso Pós-Doutorado em Teologia, que se encontra em andamento.

De início, portanto, partimos para a compreensão do Movimento Nativista em seu contexto histórico original.

\section{PODE ALGO BOM VIR DO SUL DA TERRA?}

As décadas de 60 e 70 do Século XX foram marcadas pela Guerra Fria e pelas disputas ideológicas, territoriais e econômicas das super potências capitalistas e comunistas sobre os assim chamados países de Terceiro Mundo. Enquanto os Estados Unidos se envolviam de forma trágica em um conflito armado no Vietnã, a América

\footnotetext{
${ }^{1}$ Apesar de inúmeros festivais nativistas ainda ocorrerem no Rio Grande do Sul - bem como em Santa Catarina - identificamos uma substancial transformação em termos de discurso e repertório nesses eventos. Junto a isso, verifica-se uma franca decadência na realização dos festivais, com diversos problemas quanto à sua sustentabilidade econômica e à própria relevância destes como lugar de visibilidade artística regional. Ao mesmo tempo, utiliza-se bastante o termo "nativista" atualmente simplesmente para identificar repertórios musicais caracterizados por um conteúdo regionalista e folclórico que raramente problematiza as grandes questões humanas presentes neste lugar de inspiração.
} 
Latina era sacudida por revoluções e golpes de estado que, em nome do combate a um suposto avanço comunista, acabaram instalando ditaduras militares por quase todo o continente. Essa situação durou cerca de trinta anos e, enquanto agigantava-se a censura, as perseguições, as torturas, os desaparecimentos e as injustiças, florescia aos poucos uma cultura de resistência, luta e esperança, manifestada de diversas maneiras ao longo de todo esse tempo, tendo como grande utopia uma revolução transformadora, que possibilitaria a redemocratização e a justiça social ${ }^{2}$. Talvez algumas das mais contundentes expressões do gênero tenham vindo do meio musical.

\begin{abstract}
Neste contexto, muitos compositores e intérpretes de canção popular acreditaram que por meio de suas canções, que tinham potencial de chegar a público amplos, poderiam ter um papel de destaque na propagação de ideais revolucionários, atuando como participantes fundamentais no processo de conscientização das massas. A política transbordava para todas as esferas da vida e a canção popular apareceu como uma possibilidade efetiva de intervenção política e de participação no processo de transformação social, já que seu caráter polissêmico permitiria que ela se adequasse à transmissão de ideologias ${ }^{3}$.
\end{abstract}

Nesse sentido, o marco inicial deste movimento artístico se dá em 1963, com o Manifiesto del Nuevo Cancionero, na Argentina e com o primeiro álbum de Daniel Viglietti, no Uruguai, considerada como peça inaugural da Canción Protesta da America Latina. Na mesma época o Chile conhecia a Nueva Canción Chilena, encabeçada por Violeta Parra e seus filhos Angel e Isabel. O movimento reunia jovens músicos engajados e oriundos do meio universitário na Peña Musical, taberna aberta por Violeta para reunir músicos populares e manifestações folclóricas. Essa geração de músicos comporia a trilha sonora do governo de Salvador Allende e, após o golpe de estado, sofreria cruel perseguição por parte do governo de Augusto Pinochet. Tão contundente era a força de suas músicas, que a ditadura chilena proibiu a execução de músicas com os instrumentos folclóricos típicos do país e que caracterizavam essas produções musicais. E nesse breve histórico, não se pode esquecer de Cuba, onde nasce a Nueva Trova Cubana, movimento que revelou Pablo Milanés e Silvio Rodríguez, e onde acontece, em 1967, o $1^{\circ}$ Encuentro de La Canción Protesta, que reuniu diversos expoentes da música de protesto latino-americana, formando uma verdadeira rede de influências e trocas, que rapidamente frutificou pelo continente ${ }^{4}$.

No Brasil é possível identificar características semelhantes em composições, performances e movimentos que se iniciam na década de 60 e se solidificam e fortalecem ao longo das décadas 70 e 80 . Especificamente, pode-se citar as diversas edições do Festival Internacional da Canção como lugar de fortes manifestações políticas e onde se fazem conhecer as composições e vozes de Caetano Veloso, Gilberto Gil, Chico Buarque, Nara Leão, Geraldo Vandré, Elis Regina, Taiguara e muitos outros. Nesse sentido, é suficientemente conhecida a trajetória desses artistas nacionais, as repercussões de suas obras e consequências por eles sofridas ao longo da ditadura militar no Brasil para que nos alonguemos mais nesse ponto. Apenas chamamos atenção para o fato de que essa tendência se inscreve também no contexto latino-americano das músicas de protesto - especialmente pela influência de artistas como Mercedes Sosa sobre o cancioneiro

\footnotetext{
${ }^{2}$ Esse triste período coincide com o florescimento eclesial do Vaticano II, com suas recepções latino-americanas em Medellín e Puebla e com o nascimento das Comunidades Eclesiais de Base e da própria Teologia da Libertação.

${ }^{3}$ GOMES, C. S. "Quando um muro separa, uma ponte une": conexões transnacionais na canção engajada na América Latina (anos 1960/1970), p. 23-24.

${ }^{4}$ Música engajada na América Latina. Memórias da Ditadura (online). Disponível em: $<$ http://memoriasdaditadura.org.br/musica-engajadana-america-latina/index.html>. Acesso em: 20 fev. 2018.
} 
brasileiro da época - e que a canção engajada brasileira se torna proeminente a partir da década de 70, pois o recrudescimento ditatorial ocorrido com o A.I. 5, em 1968, paradoxalmente se torna o catalisador das mais diversas manifestações de resistência e protesto contra a ditadura em seus diversos âmbitos. E aqui se encontra o ponto onde se faz necessário localizar a produção musical do Rio Grande do Sul.

\section{AQUI ME PONHO A CANTAR}

A produção musical ligada ao regionalismo gaúcho, tal como se conhece atualmente, pode ter seu início reconhecido nas pesquisas e no movimento cultural desencadeado por Barbosa Lessa, Glaucus Saraiva e Paixão Cortes, a partir de 1948, em Porto Alegre. A partir da fundação do 35 Centro de Tradições Gaúchas, os três autores desencadearam uma série de pesquisas sobre música, danças, culinária e outras expressões folclóricas que, a princípio, seriam típicas e originais do Rio Grande do Sul. Ao longo da década de 50 , como resultado dessas pesquisas, ocorreram importantes lançamentos fonográficos com o registro de canções que, se não eram tipicamente folclóricas - ou seja, sem autor específico e de domínio popular - eram de inspiração folclórica. E essa inspiração vinha, principalmente da região fronteiriça do Rio Grande do Sul, o que acabou tipificando o gaúcho como praticamente um gentílico do Rio Grande do Sul.

Os definidores do tradicionalismo foram fundamentais na fixação de uma identidade estadual, mas acabaram transmitindo para o futuro uma cosmogonia que basicamente retrata apenas as grandes propriedades rurais da Campanha e da Fronteira. Generalizando, a partir disso, na visão de hoje, todo homem rural ("gaúcho") é aquele que veste bombachas, anda a cavalo, cuida do gado, e é idealmente representado, na maioria dos festivais de música e em muitos discos, por um tipo que canta milongas e vanerões com voz gritada. Como uma prova de desconhecimento dos organizadores e das comissões de triagem dos festivais ligados ao tradicionalismo, basta dizer que durante anos músicas com o ritmo afro-gaúcho do Moçambique foram descartadas sob a justificativa de que eram "samba"... E em boa parte dos festivais o preconceito se mantém"

Mesmo trabalhando com essa visão unilateral da cultura rio-grandense, Lessa, Saraiva e Cortes acabam sendo responsáveis pela potencialização de um mercado de consumo dos bens culturais locais e pela abertura de espaço para artistas que, pouco mais adiante, se tornariam populares em nível nacional, como Teixerinha e José Mendes. Nesse sentido, a ascensão da ditadura militar no Brasil não atingiria esse segmento artístico. Muito pelo contrário: as posturas e conteúdos da música regional gaúcha, em muitos aspectos, foram praticamente integrados ao Ethos militarista, com a criação, por exemplo, do MTG, em 1966 e do Instituto Gaúcho de Tradição e Folclore, em 1974.

Conforme afirmamos anteriormente, porém, a grande efervescência musical brasileira se encontrava nos palcos do Festival Internacional da Canção, onde vários compositores, cantores e músicos do Rio Grande do Sul que não estavam ligados ao circuito cultural regionalista ansiavam por participar. Esses artistas, em sua grande maioria oriundos do ambiente urbano e universitário, fomentam uma cena musical voltada ao eixo dos festivais e do mercado fonográfico do eixo Rio-São Paulo, alimentando-se dos fenômenos musicais mais atuais à época, incluindo-se aí a música de protesto latino-americana.

\footnotetext{
${ }_{5}^{5}$ FONSECA, J. A música regional gaúcha. Parte 2 (online). Disponível em: < http://redeglobo.globo.com/rs/rbstvrs/galpaocrioulo/ noticia/2014/03/parte-2-musica-regional-gaucha-por-juarez-fonseca.html>. Acesso em: 06 fev. 2015.
} 
Como compositor, me interessava muito pela nova tendência que a gente ia armando um pouco às cegas, mas com o instinto certeiro. Procurávamos criar uma estética que fosse moderna, universal, participativa (o que era normal), mas com a novidade de ter um conteúdo ligado à nossa própria realidade, à vida de nossa cidade, de nossa geração, de nossa tradição regional transportada para o tempo atual. Podemos imaginar a variedade, a ambiguidade, a confusão que resultava disso, até pela escassez de antecedentes. Podíamos nos inspirar nas canções Alto da Bronze, Rua da Praia, Piazito Carreteiro, Os Homens de Preto e poucas mais. A chamada música de protesto de algum modo empalmava com o mito do gaúcho libertário e abria algumas possibilidades. A bossa-nova e o tropicalismo agregavam o lado moderno e atual ${ }^{6}$.

Apesar de compositores como Raul Ellwanger e Zé Caradípia terem conseguido colocar músicas suas nos festivais do centro do país e da expectativa lançada sobre a possibilidade dessa cena musical se tornar uma versão sulista do Clube da Esquina mineiro, não ocorreram os resultados esperados, talvez por causa da forte marca colocada pela música regionalista sobre as produções musicais do Rio Grande do Sul. É exatamente nesse contexto, alimentado também por uma forte penetração de uma cultura massificada alimentada pela popularização da televisão, que vai surgir, em 1971, a Califórnia da Canção Nativa de Uruguaiana. Apesar dos relatos mitificados sobre sua origem - de que o festival teria sido organizado a partir da recusa de uma canção tipicamente regional ter sido recusada em um festival de música brasileira organizado em Uruguaiana - sabe-se que a Califórnia acabou sendo o espaço necessário para a catalização de várias tendências artísticas que despontavam naquele momento. $\mathrm{O}$ mais importante é o fato de que, a partir do festival, inicia-se aquilo que será reconhecido como Movimento Nativista.

Nesta perspectiva, o Movimento Nativista pode ser visto como manifestação cultural que reinterpreta os elementos ideológicos da cultura sul-rio-grandense, dentro de uma dinâmica que tem suas contradições internas, e que é movido segundo estas forças, sem falar nas pressões externas que advêm de sua relação com o contexto geral onde está inserido, inclusive com a indústria cultural. O próprio surgimento do Nativismo, como um movimento que quis atualizar a tradição cultural gaúcha, vem mostrar que faz parte de um processo dinâmico para contrapor-se aos padrões estabelecidos pelo Tradicionalismo ${ }^{7}$.

O espaço dos festivais, assim, acabou se tornando o lugar de acolhida para boa parte da cena musical represada em centros urbanos como Porto Alegre naquela época. Isso acabou provocando um duplo movimento: artistas urbanos, com formação ou contato com o ambiente de pesquisa acadêmica, se puseram a produzir músicas com formato e conteúdo relacionado ao meio rural e o festival, nascido de demandas do próprio MTG e dos CTGs locais, acabou abrindo espaço para artistas que, de certa forma, eram estranhos àquele ambiente.

Nesse sentido, queremos aqui chamar atenção para o quanto o meio juvenil urbano e universitário, especialmente na classe média, de onde vinham esses artistas, vinha sendo marcado, entre outras coisas, pela ação de grupos e movimentos estudantis que, em boa parte, tinham suas raízes na Juventude Universitária Católica (JUC), dissolvida em 1968. Acreditamos, por isso, que, direta ou indiretamente, a geração de

\footnotetext{
${ }^{6}$ ELlWANGER, R. A Milonga dos Vencidos. In: PAdRÓs, E. S.; BARBOSA, V. M.; LOPEZ, V. A.; FERNANDES, A. S. (Orgs.). $A$ Ditadura de Segurança Nacional no Rio Grande do Sul (1964-1985): História e Memória, p. 85.

7 JACKS, N. Mídia Nativa: Indústria Cultural e Cultura Regional, p. 20.
} 
artistas urbanos e intelectualizados que acaba tomando parte nos festivais nativistas, sofre influência temática e estética das reflexões e debates ocorridos no seio desses movimentos estudantis e sociais, que, em muitas ocasiões eram também portadores das análises de conjuntura embasadas pela Teologia da Libertação. A capilaridade eclesial no interior da cultura brasileira sempre foi uma grande matriz de influência cultural e quando, após a recepção do Vaticano II nas Conferências de Medellín e Puebla, pensa-se a Igreja a partir da opção preferencial pelos pobres, certamente se inicia uma compreensão de realidade na América Latina embasada nessas diretrizes.

A imensa maioria de nossos irmãos continua vivendo em situação de pobreza e até miséria, que se veio agravando. Queremos tomar consciência do que a Igreja latino-americana fez ou deixou de fazer pelos pobres depois de Medellín, como ponto de partida para a busca de pistas opcionais eficazes em nossa ação evangelizadora, no presente e no futuro da América Latina. (DP 1135).

Nesse contexto, talvez uma das questões mais importantes seja a mudança de paradigma e, consequentemente, de imaginário e narrativa a respeito dos pobres: compreendidos como testemunhos vivos do Evangelho, a partir de um Cristo também pobre, eles se tornam protagonistas da evangelização e não mais destinatários da caridade eclesial. A pobreza em que vivem, porém, é reconhecida como fruto de relações sociais e econômicas injustas e, por isso, reconhece-se neles o anúncio da Boa-Nova de um tempo de justiça e paz e igualdade na dignidade humana.

O compromisso com os pobres e oprimidos e o surgimento das Comunidades Eclesiais de Base ajudaram a Igreja a descobrir o potencial evangelizador dos pobres, enquanto estes a interpelam constantemente, chamando-a à conversão, e porque muitos deles realizam em sua vida os valores evangélicos da solidariedade, serviço, simplicidade e disponibilidade para acolher o dom de Deus. (DP 1147)

Apesar de termos nos utilizado de trechos do documento da Conferência de Puebla, ocorrido no México, em 1979, queremos lembrar que, à época da primeira edição da Califórnia da Canção de Uruguaiana - dezembro de 1971 - já se vivia a efervescência eclesial da Conferência de Medellín, ocorrida na Colômbia em 1968. E, junto a isso, as fortes censuras, perseguições e arbitrariedades intensificadas pela ditadura militar brasileira a partir da promulgação do Ato Institucional no 5, também acontecido em 1968. A clandestinidade a que foram exilados grupos políticos e estudantis - entre eles a JUC - a partir de então, potencializaram análises de conjuntura, articulações e ações como as realizadas no seio das comunidades de base, como possíveis frentes de resistência ao regime militar. Alimentadas intelectualmente pelas produções da Teologia da Libertação, ao se utilizarem de um instrumental dialético se compreensão realidade - em detrimento de um instrumental funcionalista ${ }^{8}$ - todas essas articulações e discursos acabavam indo ao encontro de vários ideais libertários que circulavam no meio artístico daquela época. Por isso, quando esses artistas olham para o campo e buscam inspiração para retratá-lo em suas composições, acabam lançando mão de um repertório no qual os pobres e excluídos do campo se tornam protagonistas, revelando as tensões, desigualdades e injustiças existentes naquele ambiente. Crises sociais, como o êxodo rural, o empobrecimento campesino, as discriminações sofridas pelas mulheres, negros

${ }_{8}^{8}$ LIBANIO, J. B.; MURAD, A. Introdução à Teologia-perfil, enfoques, tarefas, p. 175. 
e indígenas nesse meio e, ao mesmo tempo, as esperanças que esses mesmos excluídos nutriam por transformações sociais, justiça e paz acabam sendo traduzidas liricamente com as linguagens e símbolos locais, que habitam o imaginário dos pobres do pampa.

\begin{abstract}
A Igreja está presente na região desde a primeira evangelização, mas com características muito próprias. Foi ali que os missionários jesuítas fundaram As Missões dos Sete Povos. Instituíram o cooperativismo dando grande contribuição na defesa dos indígenas, mas que foi golpeada pelo Tratado de Madri entre Portugal e Espanha, 1750, determinando que teriam que deixar seus territórios e irem para o lado controlado pelos espanhóis. Os índios resistiram, mas houve guerra, massacres e teve ali o início da dizimacão do povo guarani. Nos últimos anos, seja pela presença das Pastorais Sociais, das Semanas Sociais, das Campanhas da Fraternidade, das CEBs, muito se valoriza a agricultura familiar, os territórios das comunidades tradicionais e os remanescentes indígenas 9 .
\end{abstract}

Para além do próprio ambiente acadêmico e urbano, então, o imaginário pampeano sempre foi permeado pelas narrativas dos Sete Povos das Missões, sendo a figura do gaúcho um dos frutos dessas narrativas. O teatino errante e sem-terra, que vive das changas que lhe são oferecidas nas estâncias e mais tarde se torna o assalariado das fazendas, para em seguida viver a condição de desempregado, sem-terra e migrante rural que vai para a cidade, é o protagonista que se revela aos músicos e compositores da época, como relevante para conduzir uma reflexão sobre o contexto social mediada pela arte. E assim, podemos arriscar em afirmar que a música nativista, naquele contexto, acaba por contribuir em uma atualização da mística do povo de Deus e da História da Salvação no ambiente do Sul da Terra.

Historicamente, a relação de Deus com o povo é estreita, pois todo povo coloca seu deus como elemento essencial constitutivo de sua condição como tal. Teologicamente, o Deus de Israel, em repetidas ocasiões declara: Eu serei teu Deus e vós sereis o meu povo. Segundo a revelação, existe povo de Deus porque há um Deus do povo, em contraposição a um Deus do cosmo ou da natureza. O ser de Deus é conhecido e vivido em sua relação livre com o povo, pois Ele é aquele que é em sua doação e manifestação ao que acontece ao seu povo. Por outro lado, o povo cobra realidade, plena autoconsciência e liberdade, sendo seu povo e abrindo-se a Ele. O povo só alcança sua plenitude em referência ao Deus verdadeiro, constituído em Deus do povo ${ }^{10}$.

Ao longo do tempo, nos palcos dos festivais, essa visão entrará em conflito com o ufanismo presente em composições mais tradicionais, no qual o campo é retratado como um meio absolutamente harmônico e pacífico, o gaúcho é louvado como um herói invencível e a estância como um verdadeiro paraíso na terra, onde um generoso patrão permite que a peonada trabalhe e viva com dignidade, enquanto lhe obedecer. Por isso, as composições e performances nativistas acabam por exercer uma espécie de papel profético junto a essa realidade.

\footnotetext{
${ }^{9}$ CNBB. Campanha da Fraternidade 2017: Manual, p. 71.

${ }^{10}$ CARDENAL, R. A Igreja do Povo Crucificado. In: JÚNIOR, F. A.; MAIER, M.; CARDENAL, R. A Civilização da Pobreza: o legado de Ignácio Ellacuría para o mundo de hoje, p. 157.
} 


\section{NO CANTAR DE QUEM É LIVRE, HAY MELODIAS DE PAZ}

A produção artística tem sua expressão concretizada em uma linguagem simbólica, que transcende a simples descrição ou discussão de algo. Sendo simbólica, essa linguagem carrega consigo algumas características que a definem como tal: ela representa a realidade e reúne seus aspectos fragmentados de forma inteligível; oferece uma visão transcendente desta mesma realidade revelando tanto suas dimensões diabólicas quanto suas dimensões esperançosas; nasce de uma experiência de revelação e conversão, a partir da qual a realidade, como um todo, adquire um sentido transcendente ${ }^{11}$. Via de regra, expressões artísticas inspiram-se e concretizam-se através dessa dinâmica, guardando, por isso, várias forças religiosas em seu interior, sem que isso signifique, necessariamente, adesão a determinada confissão religiosa. Sendo uma espécie de dimensão de profundidade da cultura ${ }^{12}$, a religião acaba sendo encontrada em hábitos, linguagens, estéticas e mesmo na organização política de um povo, sem que precise estar configurada oficialmente junto a instituições formalmente religiosas. No ambiente cristão pode-se relacionar essa questão a uma teologia dos sinais dos tempos, fortemente enfatizada no Vaticano II, através da qual se busca integrar o histórico no eterno e a fé ao cotidiano.

Assim, os sinais dos tempos assinalam incidentes, acontecimentos ou fatos que fornecem um olhar sobre os amplos desdobramentos no humanitarismo e no desumanitarismo, e representam o essencial humano e o que é importante para a situação atual. Eles são fenômenos precários, nos quais a felicidade e a angústia dos homens desta era se tornam visíveis, na qual os homens devem lutar pelo reconhecimento de sua dignidade. Ao referir-nos a eles, é possível enfatizar a importância da fé. ${ }^{13}$

Através desta ótica podemos compreender uma canção como $O$ Canto dos Livres $^{14}$, de Cenair Maicá ${ }^{15}$, artista que apresentou em sua obra um forte teor de crítica social e que despontou na cena musical nativista na década de 80 . A canção se inicia com os seguintes versos: "Se meu destino é cantar, eu canto./ Meu mundo é mais que chorar, não choro./ A vida é mais do que pranto, é um sonho/ com matizes sonoros", à semelhança dos primeiros versos de El Gaucho Martín Fierro, de Jose Hernandéz "Aqui me ponho a cantar/ ao compasso desta viola,/ que o homem a quem desola/ uma pena extraordinária,/ é como a ave solitária/ que no canto se consola"16. Nisso, Maicá parece propor uma vocação e um destino do habitante pampeano que, solitário, errante e sem posses - não por opção, mas como consequência de sua exploração -, toma como sentido para a vida o cantar que traduz liricamente essa mesma vida. Por isso, esse cantar toma a forma de lamento e denúncia nos versos seguintes: "Quisera um dia cantar com o povo/ um canto simples de amor e verdade,/ que não falasse em misérias, nem guerras,/ nem precisasse clamar liberdade." Podemos compreender, nesse trecho, uma referência muito discreta à música de protesto latino-americana, com suas letras portadoras de fortes críticas às injustiças e desigualdades sociais. Na composição de

\footnotetext{
${ }^{11}$ TILLICH, P. Teologia da Cultura, p. 42-43.

${ }^{12}$ TILLICH, P. Teologia da Cultura, p. 44.

${ }^{13}$ FORNET-PONSE, Th. Respectividade e teologia dos sinais. In: JÚNIOR, F. A.; MAIER, M.; CARDENAL, R. A Civilização da Pobreza: o legado de Ignácio Ellacuría para o mundo de hoje, p. 100-101.

${ }^{14}$ MAICÁ, C. Canto dos Livres. In: Id. Canto dos Livres. (LP). Rio de Janeiro: WEA Discos, 1983.

${ }^{15}$ Nascido em Tucunduva a 03 de maio de 1947 e falecido em Porto Alegre a 02 de janeiro de 1989.

${ }^{16}$ HERNÁNDEZ, José. Martín Fierro, p. 17.
} 
Maicá esse canto, assumido como destino, não é desejável apenas como amplificação de denúncias, mas anseia tornar-se espaço de onde se amplifica a esperança, tomada como sonho de matizes sonoros.

Podemos compreender, nesse sentido, que cantar a realidade, conforme propõe a composição desde seu início, significa lançar um olhar transcendente sobre a mesma e buscar inspiração para expressar musicalmente aquilo que é sentido. Assim sendo, o cantautor ${ }^{17}$ - nesse caso específico, o gaúcho - exerce a mediação entre uma realidade imanente e o transcendente que a abarca, movido por algo que lhe toca incondicionalmente, ou seja, vivendo uma experiência de fé em uma condição análoga ao sacerdócio. Em nome de que Deus, porém, esse sacerdote perfaz sua liturgia? Em um cenário no qual comumente se encontram composições musicais ufanistas, que exaltam as belezas pampeanas, a valentia do gaúcho e coisas parecidas, seria fácil intuir que a mediação seria realizada em nome de uma idealização do Rio Grande do Sul e de uma mitificação do gaúcho. No cenário nativista em que Maicá se inseria, porém, a instância de representação é bem outra.

Um exemplo - e mais do que um exemplo - é a fé que se manifesta na religião do Antigo Testamento. Ela também tem o caráter incondicional na exigência ameaça e promessa. Mas aquilo que interessa incondicionalmente não é a nação, se bem que o nacionalismo judeu ocasionalmente lhe tentou dar esta forma distorcida; o que, porém, preocupa incondicionalmente é o Deus da justiça, que é chamado de Deus Todo-Poderoso, o Deus de toda a criação, porque para todo homem e para cada povo ele encarna a justiça ${ }^{18}$.

Perante a realidade absoluta da justiça que tem a paz como fruto e da esperança que move quem se deixa tocar por essa revelação, o Canto dos Livres continua com os seguintes versos, já em seu refrão: "No cantar de quem é livre/ hay melodias de paz./ Horizontes de ternura,/ nessa poesia de andar." Ser livre, portanto, é uma condição para cantar a paz, segundo a composição de Maicá. E, no contexto dessa composição, termos ligados à ideia de liberdade circulavam sobremaneira nos discursos e narrativas dos grupos que lutavam pela redemocratização no Brasil. O grande entendimento dessa questão se encontrava na ideia do fim da dependência econômica dos países pobres do sul em relação aos países ricos do norte. Esse foi um dos pilares da própria Teologia da Libertação, que propunha ainda a realidade do Reino como parâmetro para analisar e agir de forma transformadora sobre essa mesma realidade. A música de Cenair Maicá parece apresentar uma dinâmica similar, uma vez que, após apresentar o cantautor como alguém chamado a cantar a realidade, denunciar as injustiças presentes nesta e apresentar parâmetros para transformá-la, ele revela a promessa de um tempo novo, no qual as injustiças não mais terão vez: "E ao chegar a primavera, com as flores, / cantar um hino de paz e beleza,/ longe da prisão dos homens e da fome,/ pra não mais cantar tristezas". Há, portanto, uma esperança na promessa de uma primavera que virá e, no tempo certo, embelezará o mundo. Crendo em tudo isso, Maicá faz, ainda, sua profissão de fé: "Quem canta refresca a alma./ Cantar adoça o viver./ Assim eu vivo cantando,/ pra aliviar meu padecer.” Se a primavera ainda não chegou e o cantautor ainda padece na injustiça, o canto lhe possui como sinal vivo de esperança.

\footnotetext{
${ }^{17} \mathrm{O}$ termo cantautor é largamente utilizado para designar compositores que interpretam as próprias canções.

${ }^{18}$ TILliCH, P. A Dinâmica da Fé, p. 06.
} 


\section{CONCLUSÃO}

Ao optarmos pela canção de Cenair Maicá, obviamente deixamos de fora centenas de outras composições que poderiam exemplificar as nuances teológicas e proféticas na Música Nativista Gaúcha. Acreditamos, porém, que Canto do Livres reúne, em sua simplicidade, tudo aquilo que nos propomos a desenvolver nesse artigo: nessa canção se revela uma visão inspirada e esperançosa da realidade, que se coloca em comunhão com o horizonte do Reino e da Civilização do Amor.

O grupo de artistas que, à época, engajou-se nos festivais com suas composições, arranjos musicais e interpretações não se encontrava uniformemente engajado a um partido ou igreja e nem mesmo se consideravam um grupo coeso. Sua busca mais elementar era aquele que move qualquer artista: a de espaços legítimos para a performatização de sua arte, com o legítimo retorno financeiro daí advindo. Ao mesmo tempo, porém, os artistas que deram vida ao Movimento Nativista eram portadores - consciente ou inconscientemente - da revelação de um novo momento e de novas esperanças. E a comunicação dessas mensagens certamente bebeu nas mesmas fontes que os inúmeros movimentos sociais e comunidades de base surgidos naquele momento da história bebiam: o anseio pelo já-no-ainda-não do Reino, ainda que nem sempre ao lado do referencial eclesial.

Há muito a pesquisar sobre esse movimento cultural do Estado do Rio Grande do Sul. Esperamos, por isso, ter contribuído de alguma forma com esse pequeno escrito que, desejamos, comporá um quadro maior nas pesquisas que temos realizado.

\section{REFERÊNCIAS}

CNBB. Campanha da Fraternidade 2017: Manual. Brasília: Edições CNBB, 2016.

CARDENAL, Rodolfo. A Igreja do Povo Crucificado. In: AQUINO JÚNIOR, Francisco de; MAIER, Martin; CARDENAL, Rodolfo. A Civilização da Pobreza: o legado de Ignácio Ellacuría para o mundo de hoje. São Paulo: Paulinas, 2014.

CELAM. Evangelização no presente e no futuro da América Latina - Conclusões da III Conferência Geral do Episcopado Latino-Americano: Documento de Puebla. São Paulo: Paulinas, 1979.

ELLWANGER, Raul. A Milonga dos Vencidos. In: PADRÓS, Enrique Serra; BARBOSA, Vânia M.; LOPEZ, Vanessa Albertinence; FERNANDES Ananda Simões (Org.). A Ditadura de Segurança Nacional no Rio Grande do Sul (1964-1985): História e Memória. Porto Alegre: CORAG, 2009.

FONSECA, Juarez. A música regional gaúcha. Parte 2 (online). Disponível em: <http://redeglobo. globo.com/rs/rbstvrs/galpaocrioulo/noticia/2014/03/parte-2-musica-regional-gaucha-por-juarezfonseca.html>. Acesso em: 06 fev. 2015.

FORNET-PONSE, Thomas. Respectividade e teologia dos sinais. In: AQUINO JÚNIOR, Francisco de; MAIER, Martin; CARDENAL, Rodolfo. A Civilização da Pobreza: o legado de Ignácio Ellacuría para o mundo de hoje. São Paulo: Paulinas, 2014.

GOMES, Caio de Souza. “Quando um muro separa, uma ponte une”: conexões transnacionais na canção engajada na América Latina (anos 1960/1970). Dissertação (Mestrado em História) Faculdade de Filosofia, Letras e Ciências Humanas da Universidade de São Paulo, 2013.

HERNÁNDEZ, José. Martín Fierro. Trad. de João Otávio de Nogueira Leiria. Porto Alegre: Martins Livreiro, 2004.

JACKS, Nilda. Mídia Nativa: Indústria Cultural e Cultura Regional. Porto Alegre: Editora Universidade/UFRGS, 2003.

LIBANIO, João Batista; MURAD, Afonso. Introdução à Teologia - perfil, enfoques, tarefas. 6. ed. São Paulo: Loyola, 2007. 
MAICÁ, Cenair. Canto dos Livres. In: MAICÁ, Cenair. Canto dos Livres (LP). Rio de Janeiro: WEA Discos, 1983.

Música engajada na América Latina. Memórias da Ditadura (online). Disponível em: <http:// memoriasdaditadura.org.br/musica-engajada-na-america-latina/index.html>. Acesso em: 20 fev. 2018 .

TILLICH, Paul. Dinâmica da Fé. São Leopoldo: Sinodal, 1974.

TILLICH, Paul. Teologia da cultura. São Paulo: Fonte E, 2009.

Recebido em: 02/05/2018

Aprovado em: 29/06/2018

\section{Correspondência para:}

Renato Ferreira Machado

Av. Senador Salgado Filho, 8500 - Cond. Buena Vista, casa x4

Bairro Jardim Krahe

94440-000 Viamão, RS, Brasil 